\title{
More news from IMPROVE-IT (IMProved Reduction of Outcomes: Vytorin Efficacy International Trial)
}

\author{
Niki Katsiki, ${ }^{1}$ Vasilios G. Athyros, ${ }^{1}$ Dimitris P. Mikhailidis ${ }^{2}$
}

\begin{abstract}
${ }^{1}$ Second Propedeutic Department of Internal Medicine, Medical School, Aristotle University of Thessaloniki, Hippokration Hospital, Thessaloniki, Greece; ${ }^{2}$ Department of Clinical Biochemistry (Vascular Prevention Clinics), Royal Free Hospital Campus, University College Medical School, University College London, London, UK
\end{abstract}

The IMProved Reduction of Outcomes: Vytorin Efficacy International Trial (IMPROVE-IT) reported a significant reduction in first primary endpoint (PEP) post-acute coronary syndrome (ACS) in patients $(\mathrm{n}=18,144)$ on ezetimibe + simvastatin compared with placebo + simvastatin. ${ }^{1}$ The low-density lipoprotein cholesterol (LDL-C) levels in the combination group were significantly lower than in the monotherapy group (53.7 vs $69.5 \mathrm{mg} / \mathrm{dl}$; 1.4 vs $1.8 \mathrm{mmol} / \mathrm{l}$ ).

A recent analysis of IMPROVE-IT considered all PEP events [cardiovascular (CV) death, myocardial infarction (MI), stroke, unstable angina leading to hospitalization, coronary revascularization $\geq 30$ days post-randomization]. ${ }^{2}$ The duration of the trial was a median of 6 years (25th, 75 th percentiles: 4.3 and 7.1 years). Often trials only consider the first vascular event. ${ }^{2}$ However, this may not represent the clinical situation, since patients with ACS may have recurrent events (except when the initial event is death). Assessing all events is an advantage in trials which last longer, as for IMPROVE-IT.

Not surprisingly, the all events analysis ${ }^{2}$ of IMPROVE-IT is more impressive than the initial first

Address for correspondence:

D.P. Mikhailidis, BSc, MSc, MD, FCPP, FCP, FRSPH, FFPM,

FRCP, FRCPath, Department of Clinical Biochemistry, Royal Free Hospital Campus, University College London Medical School, University College London (UCL), Pond Street, London NW3 2QG, UK; Tel.: +44 207830 2258,

Fax: +44 207830 2235, E-mail: MIKHAILIDIS@aol.com

Received: 22-02-2016, Accepted: 25-02-2016 event only analysis. ${ }^{1}$ There were 9,545 total PEP events $[5,314(56 \%)$ first events $+4,231(44 \%)$ subsequent events]. Thus, the first event analysis did not include $>4000$ events. Total PEP events were significantly reduced by $9 \%$ with ezetimibe/simvastatin vs placebo/ simvastatin [incidence-rate ratio (RR): 0.91; 95\% confidence interval $(\mathrm{CI}): 0.85$ to $0.97 ; \mathrm{p}=0.007]$. There were an additional 251 fewer events in the combination therapy group after considering all events. This should be added to the 170 first events prevented making a total of 421 fewer events in the combination therapy group. This translates into 11 total PEP events prevented with ezetimibe plus simvastatin compared with simvastatin monotherapy for every 100 patients treated for 10 years.

In the all events analysis ${ }^{2}$ of IMPROVE-IT, the exploratory composite endpoint of $\mathrm{CV}$ death, $\mathrm{MI}$ or stroke was significantly reduced (RR: $0.88 ; 95 \% \mathrm{CI}$ : 0.81 to $0.96 ; p=0.002)$. The reduction in total events was mainly driven by a decrease in non-fatal MI (RR: 0.87 ; $95 \%$ CI: 0.79 to $0.96 ; \mathrm{p}=0.004)$ and non-fatal stroke (RR: $0.77 ; 95 \%$ CI: 0.65 to $0.93 ; \mathrm{p}=0.005$ ).

When the total number of PEP events were considered, $70.7 \%$ of the participants had no events, $16.6 \%$ had 1 event, $7.3 \%$ had 2 events and $5.4 \%$ had $\geq 3$ events. The greatest number of events was 14 events in 2 patients; $13 \%$ of the 18,144 subjects had $>1$ PEP event.

Compared with patients with only 1 event, those with multiple events had more comorbidities at study 
entry, including hypertension and diabetes mellitus (DM), and more had previously experienced MI, angina or revascularization.

The all events analysis ${ }^{2}$ of IMPROVE-IT also provides additional evidence for the LDL-C hypothesis (i.e. lower is better). The 1-month LDL-C levels were lowest in those without a subsequent PEP event and highest in those with $>1$ PEP event (mean 58.3 $\mathrm{mg} / \mathrm{dl}$ for no event, $59.6 \mathrm{mg} / \mathrm{dl}$ for 1 event and 60.1 $\mathrm{mg} / \mathrm{dl}$ for $>1$ event; $\mathrm{p}<0.001$ for 3 -way comparison). However, there was no difference when LDL-C levels in those with 1 PEP event were compared with those with $>1$ PEP event. An LDL-C of $<70 \mathrm{mg} / \mathrm{dl}$ at 1 month was most common among subjects without a PEP event during the trial compared with subjects with 1 or $>1$ event ( $p<0.001$ for 3 -way comparison). However, there was no significant difference when comparing subjects with $1 \mathrm{PEP}$ event with those who had $>1$ PEP event.

The all events analysis ${ }^{2}$ of IMPROVE-IT suggests that sustained long-term lipid lowering treatment that achieves low LDL-C levels is necessary to achieve a continuous decrease in events. However, this all events analysis ${ }^{2}$ also has limitations, as outlined by the authors. For example, after a first nonfatal event, many subjects discontinue their blinded study drug, which may influence subsequent events occurring off study drug. To address this limitation, an ontreatment analysis was performed ${ }^{2}$ which showed findings consistent with the intent to treat analysis.

The IMPROVE-IT results ${ }^{1}$ suggest a greater benefit for patients with DM in terms of event reduction. Furthermore, there was no increase in statin-associated new onset DM (NOD) in the combination therapy group despite achieving significantly lower LDL-C levels [http://www.tctmd.com/show aspx?id=130400; abstract presented at the European Society of Cardiology meeting, London, August 2015]. There may be several reasons for this result. ${ }^{3}$ Because there are risk factors that increase the risk of NOD, it would be of interest to assess the incidence of NOD in patients with different numbers of these risk factors. The rationale is that there is some evidence of beneficial effects of ezetimibe on insulin resistance. ${ }^{3}$ As one predictor of statin-associated NOD is the duration of statin treatment, the duration of IMPROVE-IT (up to 7.1 years) may prove to be an advantage. There is also evidence that lowering LDL-C levels with statins helps preserve kidney function. ${ }^{4}$ This effect could extend to ezetimibe. ${ }^{5,6}$ However, this renal effect of statins or ezetimibe is only likely to be seen in those with some degree of chronic kidney disease. Again, the duration of IMPROVE-IT could prove useful because there is evidence that statins may not protect kidney function in long-term studies. ${ }^{7}$

The cost effectiveness of ezetimibe will increase when this drug becomes a generic product in several countries within the next few years. This drug remains the only add-on to a statin with convincing event-based evidence. ${ }^{8}$

It is surprising that with this level of evidence the Endocrinologic and Metabolic Drugs advisory committee of the food and drug administration did not accept the recommendation of ezetimibe use as addon to statin therapy in coronary heart disease patients [http://www.medscape.com/viewarticle/855958?nlid $=93603 \_2566 \&$ src $=$ wnl_edit_medp_card $\& u a c=1825$ 15FR\&spon $=2 \&$ impID $=921006 \&$ faf $=1]$. In contrast, the European Society of Cardiology guidelines for the management of acute coronary syndromes in patients presenting without persistent ST-Segment elevation recommend ezetimibe as the only add-on to statins. ${ }^{9}$

A survey of a large health care system $(n=219,625$ patients with ACS) concluded that $31.6 \%$ could qualify for ezetimibe if used outside of the strict IMPROVE-IT trial inclusions. ${ }^{10}$ It follows that defining the role of ezetimibe in patients with ACS already taking highintensity statins or those with statin intolerance is important. In this context, statin intolerance remains a clinically relevant problem. ${ }^{11}$

Undoubtedly there will be further sub-analyses of the IMPROVE-IT trial. Obviously, there is a need to consider the effect of additional events on quality of life and health expenditure. An economic analysis of IMPROVE-IT has been planned.

\section{REFERENCES}

1. Cannon CP, Blazing MA, Giugliano RP, et al, 2015 IMPROVE-IT Investigators. Ezetimibe Added to Statin Therapy after Acute Coronary Syndromes. N Engl J Med 372: 2387-2397.

2. Murphy SA, Cannon CP, Blazing MA, et al, 2016 
Reduction in Total Cardiovascular Events With Ezetimibe/Simvastatin Post-Acute Coronary Syndrome: The IMPROVE-IT Trial. J Am Coll Cardiol 67: 353-361.

3. Katsiki N, Athyros VG, Karagiannis A, Mikhailidis DP, 2016 Statins and Type 2 Diabetes Mellitus: An Update After 1 Year. Curr Pharm Des. [Epub ahead of print] PubMed PMID: 26806344.

4. Athyros VG, Katsiki N, Karagiannis A, Mikhailidis DP, 2015 Statins can improve proteinuria and glomerular filtration rate loss in chronic kidney disease patients, further reducing cardiovascular risk. Fact or fiction? Expert Opin Pharmacother 16: 1449-1461.

5. Migdalis I, Efthimiadis A, Pappas S, Alexopoulos D, Vlasserou F, Mikhailidis DP, 2009 Clinical experience with ezetimibe/simvastatin in a Mediterranean population. Curr Med Res Opin 25: 2571-2576.

6. Gazi IF, Daskalopoulou SS, Nair DR, Mikhailidis DP, 2007 Effect of ezetimibe in patients who cannot tolerate statins or cannot get to the low density lipoprotein cholesterol target despite taking a statin. Curr Med Res Opin 23: 2183-2192.

7. Acharya T, Huang J, Tringali S, Frei CR, Mortensen
EM, Mansi IA, 2016 Statin Use and the Risk of Kidney Disease With Long-Term Follow-Up (8.4-Year Study). Am J Cardiol 117: 647-655.

8. Serban MC, Banach M, Mikhailidis DP, 2016 Clinical implications of the IMPROVE-IT trial in the light of current and future lipid-lowering treatment options. Expert Opin Pharmacother 17: 369-380.

9. Roffi M, Patrono C, Collet JP, et al, 20162015 ESC Guidelines for the management of acute coronary syndromes in patients presenting without persistent STsegment elevation: Task Force for the Management of Acute Coronary Syndromes in Patients Presenting without Persistent ST-Segment Elevation of the European Society of Cardiology (ESC). Eur Heart J 37: 267-315.

10. Virani SS, Akeroyd JM, Nambi V, et al, 2015 Implications for Ezetimibe Therapy Use Based on IMPROVE-IT Criteria. Am J Med 128: 1253-1256.

11. Banach M, Rizzo M, Toth PP, et al, 2015 Statin intolerance - an attempt at a unified definition. Position paper from an International Lipid Expert Panel. Arch Med Sci 11: 1-23. 